\title{
LLNL Small-Scale Drop-Hammer Impact Sensitivity Test
}

\author{
L. Richard Simpson \\ M. Frances Foltz
}

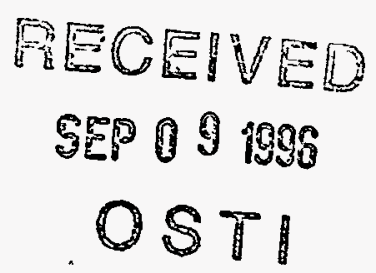

January 1995

This is an informal report intended primarily for internal or limited external distribution. The opinions and conclusions stated are those of the author and may or may not be those of the Laboratory.

Work performed under the auspices of the Department of Energy by the Lawrence Livermore National Laboratory under Contract W-7405-Eng-48. 


\section{DISCLAIMER}

This document was prepared as an account of work sponsored by an agency of the United States Government. Nelther the United States Government nor the University of California nor any of their emplojees, makes any warranty, express or Implied, or assumes any legal liabillty or responsibility for the accuracy, completeness, or usefulness of any information, apparatus, product, or process disclosed, or represents that its use would not infinge privately owned rights. Reference herein to any spedfic commercial products, process, or service by trade name, trademark, manufacturer, or otherwise, does not necesserily constitute or imply its endorsement, recommendation, or favoring by the United States Government or the University of Calffornia. The vlews and opinions of authors expressed herein do not necessarily state or reflect those of the United States Government or the University of Callfornia, and shall not be used for advertising or product endorsement purposes.

This report has been reproduced directly from the best avaliable copy.

Avallable to DOE and DOE contractors from the Office of Scientific and Technical Information P.O. Box 62, Oak Rldge, TN 37831

Prices avaliable from (615) 576-8401, FTS 626-8401

Avallable to the public from the

National Technical Information Service

U.S. Department of Commerce

5285 Port Royal Rd.

Springfield, VA 22161 


\section{DISCLAIMER}

Portions of this document may be illegible in electronic image products. Images are produced from the best available original document. 


\title{
LLNL Small-Scale \\ Drop-Hammer \\ Impact Sensitivity Test
}

\author{
L. Richard Simpson, and M. Frances Foltz \\ Lawrence Livermore National Laboratory \\ P.O. Box 808, L-281 \\ Livermore, CA 94550
}

\begin{abstract}
Small-scale saftey testing of explosives and other energetic materials is done to determine their sensitivity to various stimuli including friction, static spark, and impact. This testing is typically done to discover potential handling problems for either newly synthesized materials of unknown behavior or materials that have been stored for long periods of time. This report describes the existing "ERL Type 12-Drop Weight Impact. Sensitivity Apparatus," or "Drop Hammer Machine," and the methods used to determine the impact sensitivity of energetic materials. Also discussed are changes made to both the machine and methods since the inception of impact sensitivity testing at Lawrence Livermore National Laboratory in 1956. The accumulated data for the materials tested is not listed here, the exception being discussion of those specific materials (primary calibrants: PETN, RDX, Comp-B3, and TNT; secondary calibrants: $K-6, R X-26-A F$, and TATB) used to calibrate the machine.
\end{abstract}




\section{Introduction}

When new explosives are developed or when existing explosives need to be examined for long-term changes in sensitivity, they must be run through a series of

Small-Scale Safety Tests to determine their sensitivity to various stimuli, such as friction, static spark, and impact. At the Lawrence Livermore National Laboratory, a special laboratory for this testing is located in the High Explosive Application Facility (HEAF).

\section{Impact Test}

One of the tests done in HEAF is the Impact Test. This test is done on a machine called an "ERL Type 12 Drop Weight Sensitivity Apparatus", more commonly. called a "Drop-Hammer Machine".

The purpose of the test is to determine the impact sensitivity of small samples of explosives. A small sample (35-mg) of explosive is placed between the anvil and striker of the machine and a weight is dropped on the striker. A microphone transmits the noise response to a peak recording voltmeter and the result is recorded in a notebook. The height of the weight is varied for each test in a series as determined by the preceeding result. A "50\% Impact Height," or $\mathrm{Dh}_{50}$, is calculated using this series of data and a predetermined "go" sound level of reaction.

\section{Apparatus}

The machine used by the Lawrence Livermore National Laboratory is based on the design developed by the Explosives Research Laboratory (ERL) ${ }^{1}$ of the National Defense Research Committee. It is referred to as an "ERL Type 12 Drop Weight Sensitivity Apparatus".2,3 The machine has undergone many design changes since the apparatus was described in the Manual of Sensitiveness Tests. ${ }^{4}$ The apparatus consists of a steel weight free-falling from a height onto a steel "striker" pin which in turn transmits the impact to the explosive test sample (Figure 1). The sample rests without containment either on sandpaper (Test 12A) or on the "bare anvil" (Modified Test 12B). A special procedure exists for liquids. 
Figure 1

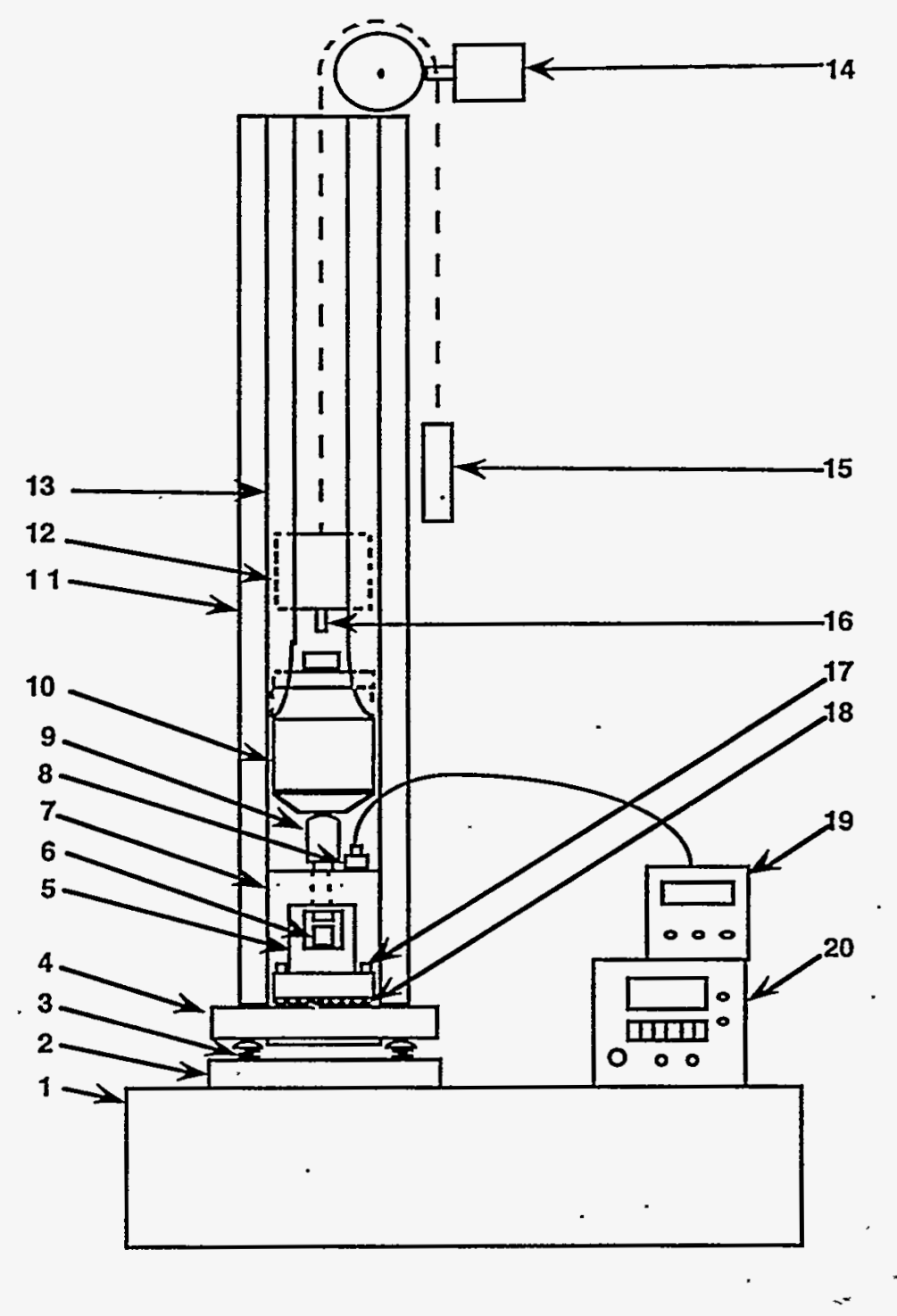

Components of the ERL Type 12 Drop Weight Sensitivity Apparatus, or Drop: Hammer.Machine: (1) massive (top $3^{\prime} \times 1^{\prime} \times 3^{\prime}$; base $3^{\prime} \times 2^{\prime} \times 2^{\prime} 6^{\prime \prime}$ ) concrete table, (2). $14^{\prime \prime} \times 14^{\prime \prime} \times 4^{\prime \prime}$ steel plate, bolted to table, (3) 4 adjuster (leveling) screws to bring drop weight into plumb, (4) a second $14^{\prime \prime} \times 14^{\prime \prime} \times 4^{\prime \prime}$ steel base plate, (5) tool holder for lower anvil and striker, (6) lower anvil, (7) containment box, (8) microphone, (9) upper anvil, or striker, (10) $2.5 \mathrm{~kg}$ (or $1.1 \mathrm{~kg}$ for liquids) drop weight, (11) support rails for guide tube, (12) drop mechanism, (13) guide tube, (14) height adjustment motor, (15) balance weight for drop weight, (16) "ball-lock" pin which holds/releases drop weight, (17) eight 3/8-16 socket head cap screws to hold tool assembly and screen down, (18) 16-mesh SS wire screen to reduce rebound, (19) voltmeter for microphone, (20) height control. 
The drop weight that was originally used at ERL was $5-\mathrm{kg}$ of solid steel. The drop weight used at LLNL is hollow and weighs $2.5-\mathrm{kg}$, half of this mass consisting of loose \#6 lead shot. This shot-loaded weight exhibits very low rebound. A single impulse through the sample is desired and is achieved by matching the mass of the striker to that of the falling weight. The shot-filled weight minimizes the second impulse from rebound. A similar 5-kg weight is also available for testing less sensitive explosives.

A steel tube, with an inside diameter slightly larger than the outside diameter of the drop weight, guides the drop weight and allows it to free-fall. The original machine ${ }^{1}$ had guide rails with rollers on the drop weight. This arrangement was unsatisfactory because it was difficult to maintain the alignment and spacing of the rails, resulting in the drop weight falling off the rails on occasion.

An electric hoist positions the drop mechanism, which suspends the drop weight at any desired height up to $177-\mathrm{cm}$. This drop mechanism consists of a solenoid operating a "ball-lock" pin type mechanism when the "drop" button is pushed to release the drop weight. An automatic solenoid operated "safety bar" is inserted into the guide tube at the $50-\mathrm{cm}$ height to stop the drop weight should it happen to fall accidentally during set-up. The safety bar is automatically withdrawn when the drop weight is released. An electronic height controller is used to alter the height of the drop weight. In it is included the thumb-wheel controls used to change the height and a digital read-out of the height. Also included are manual controls for the safety bar, the drop weight release control, the control for the vacuum system solenoid and a manual height control.

The "striker" for the 12A and 12B tests is $~ 9.5$-in. long and weighs $2.5-\mathrm{kg}$. The upper half is 2.0-in. in diameter and has a spherical radius on the top so that the drop weight always strikes the center of the striker. The lower half is 1.25-in. in diameter. The "striker" for the Liquid Test is also $~ 9.5$-in. long but weighs $1.1-\mathrm{kg}$. This striker slides into a holder or collar, than in turn fits into the flanged tool holder described below. The "anvil" is used for all tests is 1.25-in. in diameter and 2.5-in. long. Strikers and anvils are made of tempered tool steel hardened to between 58 and 62 on the Rockwell $C$ hardness scale, for durability. . The top and bottom faces of the anvil are plane and parallel to within a tolerance of 0.00015-in. Likewise, the bottom face of the striker is precision ground so that the plane of its face is within $0.0001-i n$. of the anvil 
top face. This precision is necessary to prevent any "pinching" action on the explosive sample due to the anvil faces being out of parallel. In the past, worn anvils were frequently ground to smoothness by "figure-eight" movements of the anvil over 600-grit sandpaper. This is no longer done because it can distort the anvil surfaces out of planarity. The striker and anvil are surface ground to a 16- $\mu$ in. finish, except for the bottom face of the striker and the top face of the anvil which are ground to a 4- $\mu$ in. finish.

The flanged tool holder is a single piece of machined alloy-steel. It is precision bored to accept the lower anvil and striker and has a rectangular window milled perpendicular to the plane of the mating surface of the anvil and striker, thus providing an access hole to position the explosive test sample. The top of the anvil is 5 -in. above the base of the tool holder. The tool holder is attached to the base by bolts through a bolt circle in the flange with 16-mesh stainless steel wire screen between the tool holder and base: The base itself is a steel block 14-in. square by 4 -in. thick. The base is mounted on another steel block of the same dimensions which is bolted to a massive (top 3-ft $\times 1-\mathrm{ft} \times 3-\mathrm{ft}$; base 3-ft $\times 2-\mathrm{ft} \times 2-\mathrm{ft} 6-\mathrm{in}$.) concrete foundation and can be leveled by adjusting screws between the two blocks. The base is not acoustically coupled to the foundation: its bottom surface is essentially a free surface which will reflect as rarefactions the compressional elastic waves due to the falling weight.

A containment box surrounds the anvil holder to shield the operator from flying debris and any gasses produced by the test sample. The box is the same height as the anvil holder, with a hole in the top to allow the top of the anvil holder to protrude a few millimeters. Access to the top of the anvil holder is necessary for removing and replacing the striker. A suction hose is connected to the side of the containment box to draw off smoke and fumes produced by reactions during the tests. A large industrial vacuum cleaner provides continuous air flow during operation. A water trap and paper filter are included in the system to prevent explosive.contamination of the vacuum system.

\section{Instrumentation}

From November 1956 to March 1979, use of (undocumented) amplification electronics with a Consolidated Electrodynamics type 4-340 microphone gave a "go" sound level of $0.50-\mathrm{V}$ (maximum meter reading of $1.0-\mathrm{V}$ ). From March 1979 until 
October 1994, the sound level of a drop event was monitored with the same microphone amplified by a Tektronics TM 501 power module. A memory volt meter (Micro Instrument Co., model 5203) recorded the peak voltage of the amplified microphone output. Over the 1979 to 1994 time period, the "go" sound level was defined as $480 \mathrm{mV}$. When this microphone stopped working reliably (i.e. the signal level began drifting over the course of several sample tests), it was replaced in October 1994 by a quartz microphone with built-in amplifier (PCB Piezotronics model 106B50 with two model 451B Digital Peakmeters to cover the total range of 1 to $10-\mathrm{V}$ ). The transition from one microphone to the other was dependent on the definition of the "go" sound level and is described in Appendix A.

The microphone is mounted in the shielding which surrounds the tool holder, its axis parallel to that of the tools and offset 3-in. behind the toolholder. The plane of the face of the microphone is 5 -in. above the plane of the anvil face. This location was chosen instead of the acoustically preferred position in the back of the box in the plane of the reacting sample, to avoid damage from shrapnel.

\section{Pretest Procedure}

No attempt is made to condition the explosives unless they are known to be unusually hygroscopic. Storage in the test lab for an hour or so is considered acceptable for most explosives. Samples known to be hygroscopic are kept in a desiccator until needed. The building housing the test equipment has its temperature controlled to $68 \pm 3^{\circ} \mathrm{F}\left(19^{\circ} \mathrm{C}\right)$. Building humidity is not controlled, ranging from a very low $10 \%$ relative humidity to $\sim 80 \%$.

Samples of explosives weighing $35 \pm 2 \mathrm{mg}$ are charged into a 3/16-in. diameter multicavity ("shotgun") die and cold pressed for three minutes at 30,000-psi. Their final thickness depends upon the density obtained. Not all materials press well into pellets, nor is it always desirable. Some rubbery formulations will be tested as small chunks cleaved from the bulk sample. Other materials that don't hold together as pellets will be tested as piles of powder. Numbers obtained with powders are generally consistent with pressed materials, but with more scatter in the data. 


\section{Procedure}

The LLNL impact test is employed for two purposes. First, it is one of several safety tests used to determine whether a material may or may not be safely handled if reasonable care is exercised. Second, it is used to compare the relative impact sensitivities of various explosive materials when response is fairly strong. ${ }^{5}$ High precision is unnecessary in the first case, for which the procedure is varied to suit the nature of the test explosive. Many times new explosives are made in one or two gram batches, so testing is necessarily limited to five to ten drops. In this case, the $\mathrm{Dh}_{50}$ value will not be statistically meaningful. The requestor will be notified of this value as well as the minimum height that a "go" was recorded for. Tests of the second type are done according to a strict routine by the specific steps are outlined in Appendix $\mathrm{B}_{\text {. }}$

The sample for Test $12 \mathrm{~A}$ is placed on a 1-in. square of Carborundum "fine" (120-grit) flint paper. The striker is gently lowered onto the explosive sample. The drop weight is then released from a height dictated by the sequential "up and down" or Bruceton 6,7 method. Height increments are typically 0.05 on a logarithmic scale. If the individual drop numbers are too scattered (more than six height levels), the drop height log increment should be changed to 0.10 or 0.15 to reduce the scatter - both tabulated heights and procedural details are in Appendix B. The final result is a mean height for "go" events called the " $50 \%$ Impact Height" or Dh 50 , reported in centimeters. A series of at least 20 drops is done, although 30 drops reduces the variance of $D_{50}$. Since the shotgun die produces fifteen parts simultaneously, and all or a symmetrical array of the holes need to be filled to press uniform pellets, 30 pellets can quickly be pressed. Shredded sandpaper and HE residue are scraped off the striker and anvil after each drop. The striker and anvil are then carefully cleaned with solvent (acetone) between each drop to remove any final residue. When there is an appreciable change in the surface smoothness of the tools (i.e. the surface roughness is determined with the fingertips), they are replaced by a new set. Roughened surfaces tend to increase the $50 \%$ drop height as much as several centimeters over the accepted value. Used sets of anvils are sent out for re-grinding. Temperature and humidity variations can sometimes change the sensitivity of explosives, so the temperature and humidity are recorded for each test.

The Modified Test $12 \mathrm{~B}$ is conducted without sandpaper: the explosive sample is placed directly on the anvil. The original Test $12 \mathrm{~B}$ used roughened anvils, not 
smooth ones as employed here. It was found that the roughened anvil surfaces prepared for this test changed with use, causing the drop height to drift. Otherwise, the Modified $12 \mathrm{~B}$ test is done exactly as the $12 \mathrm{~A}$ test. The Modified $12 \mathrm{~B}$ test is not often used today because the $12 \mathrm{~A}$ test is considered a worst case test. The Test $12 \mathrm{~B}$ is appropriate with high explosives that flow easily (e.g. soft or with a low melting point). These materials can interact with the glue in the sandpaper-used in Test $12 \mathrm{~A}$, giving an artificially low drop height. Likewise, easily malleable explosives can flow around the sand particles under impact, giving an erroneous and misleading high drop height.

The Liquid test is done with a special $1.1-\mathrm{kg}$ striker which is deliberately impedance mismatched with the drop weight. The mismatch is essential to produce tension waves in the striker that will create cavitation bubbles in the liquid, which in turn leads to reaction when they are closed. Cavitation is not needed to cause reaction in all liquid energetic materials, however. For example, the sensitive liquid explosive nitroglycerin (NG) does not require cavitation to react nor does the energetic liquid plasticizer $1,2,3-\operatorname{Tris}(\alpha, \beta$-bis[difluoramino]-ethoxy)propane (TVOPA). The top surface of the lower anvil is lightly greased (silicone vacuum grease) to make the liquid form a bead. One drop of the liquid explosive is placed in the center of the bare anvil. The striker is held $1 / 8$-in. above the anvil by a spring clamp so that it does not touch the drop of explosive. When the weight is released, the striker is forced down onto the explosive sample. The rest of the test (e.g. height increments, sound detection) is the same for solid HE's.

\section{Data Interpretation and Evaluation}

A "go" response is due to sufficient reaction to produce a sound level registering a value equal to or greater than a previously defined reading on the volt meter. A "no go" is a sound intensity which causes the volt meter to read less than this value. The meter reading of the sound level is recorded because it gives some additional information on the nature of the reaction. The "go" sound level was historically defined as $480-\mathrm{mV}$ for the data collection period of March 1979 to October 1994, and redefined to $1.3-V$ when both microphone and amplification electronics were changed. How these values were determined is described in Appendix $A$.

The method used to calculate the $\mathrm{Dh}_{50}$ is the "up and down" or Bruceton method. 6,7 In this method, a series of test levels is chosen with equal log spacings 
between drops (see Table in Appendix B). The first level is chosen by guessing an initial height ho. If there is no prior impact data to work from, either a $50-\mathrm{cm}$ height is chosen as the first level or the requestor makes a guess of sensitivity relative to a known compound so a comparable initial height can be chosen. If this sample reacts to give a sound level at or above the "go" level, the second sample will be tested at a level $h_{-1}$ several values below $h_{0}$. Otherwise the next sample height will be $h_{1}$ several values above ho. Choosing heights several steps away from the initial drop height is only done to bracket the range - these data points should not be used in the calculation, which is based on evenly spaced intervals. Thereafter, drop heights are chosen only one step away from the previous height. In this way; each sample will be tested at a height just above or below that of the previous sample depending on whether it was a "go" or not. The results are recorded in a notebook. and a spreadsheet with $x$ 's as "go's" and o's as "no-go's". For calculating Dh 50 and its standard deviation, only the "go's" or "no go's" are used, depending on which has the smaller total. Whichever is chosen is thereafter referred to as "events" in the calculation. The formulae 6,8 used to calculate the $50 \%$ drop height $\left(\log \mathrm{Dh}_{50}=\mathrm{m}\right)$ and its standard deviation ( $\pm \sigma=\log s$ ) are as follows: 8

$$
m=y+d \times\left[\frac{\sum_{i=0}^{i=n-1} N_{i} \times i}{\sum_{i}^{n} N_{n}} \pm 0.5\right]
$$

and

$$
s=1.620 \times d \times\left[\frac{\sum_{1}^{n} N_{n} \sum_{i=0}^{i=n-1} N_{i} \times i^{2}-\left(\sum_{i=0}^{i=n-1} N_{i} \times i\right)^{2}}{\left(\sum_{1}^{n} N_{n}\right)^{2}}+0.029\right]
$$

where the \pm 0.5 in the first equation is chosen as negative or positive depending on whether the "go's" or "no go's" are chosen as the "events" for the calculation, and

$N=$ number of events at each level

$\mathrm{n}=$ number of event levels

$y=$ normalized lowest height $\left(h_{0}\right)=\log h_{0}$

$d=\log \frac{h_{1}}{h_{0}}$ (will be typically 0.05 , occasionally 0.10 , and only rarely 0.15 ) 
$\mathrm{i}=$ level number (i.e. the number of drops at six equally spaced heights starting with the lowest height used for " $y$ ")

A sample calculation for one of the calibrants and the drop height sequence table used to select heights during testing are given in Appendix $C$.

The results of a Bruceton method test permit ranking by impact sensitivity of a particular explosive with respect to other explosives according to their $50 \%$ heights. A standard deviation is assigned to each $\mathrm{Dh}_{50}$ calculated. The user should attach little importance to small batch-to-batch or HE-to-HE differences in $\mathrm{Dh}_{50}$ due to unavoidable scatter in the noise response (i.e. microphone meter reading) vs. drop height data which it is based on (Figure $2 a$ and $2 b$ ). Significant differences are indicated by the standard deviation.

Figure 2
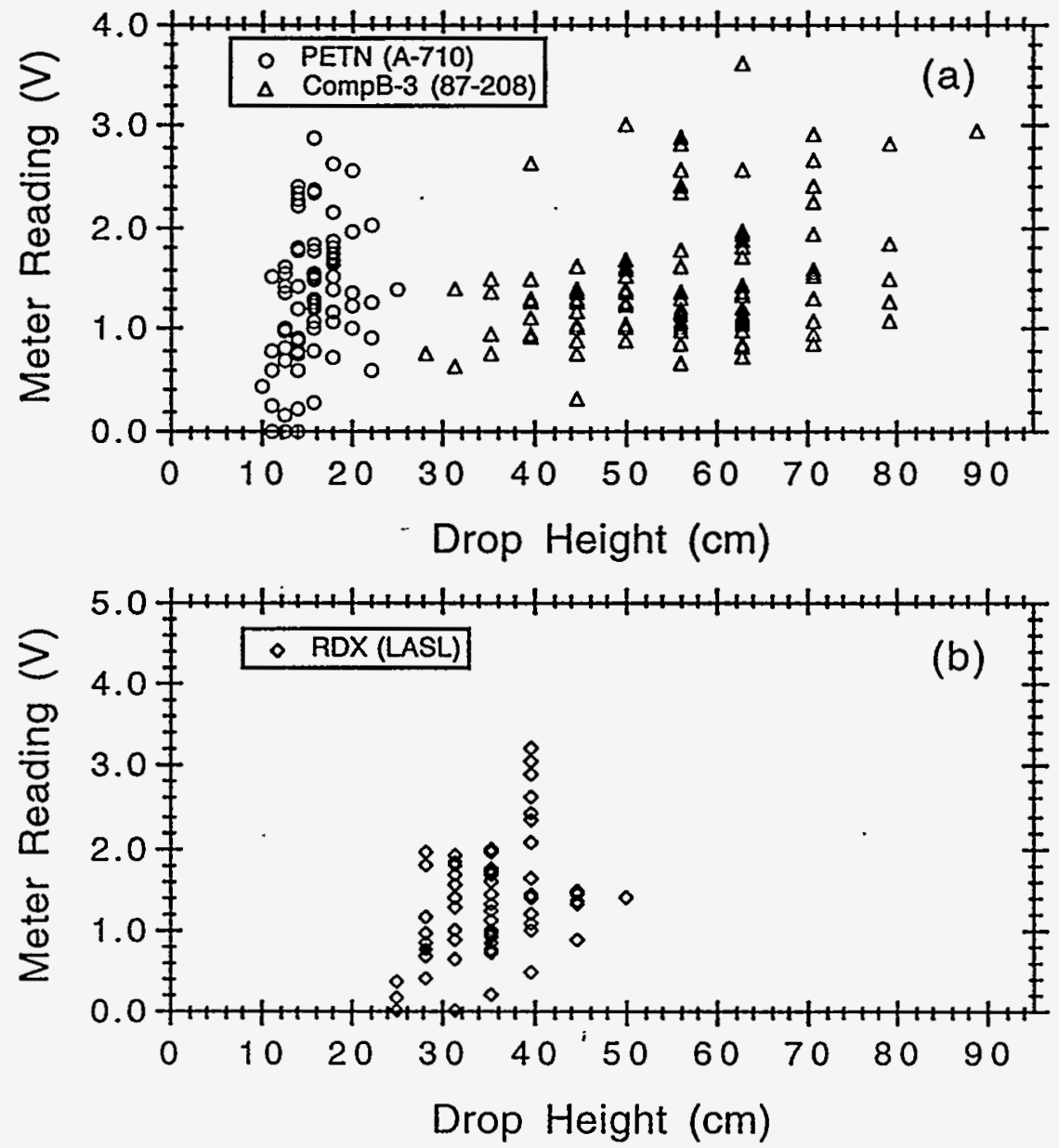

Meter reading (volts) vs. drop height $(\mathrm{cm})$ for three calibrants: (a) PETN (A-710) and Comp B-3 (87-208), and (b) RDX (special LASL batch). 
Relative ordering of explosives by their $50 \%$ explosion height is often different in the $12 \mathrm{~A}$ and Modified $12 \mathrm{~B}$ tests - the $12 \mathrm{~B}$. $\mathrm{Dh}_{50}$ is usually higher. The user should consider that an inversion (i.e. Test $12 \mathrm{~B} \mathrm{Dh}_{50}$ lower than the Test $12 \mathrm{~A}$ value) may indicate unusual explosive behavior. The material properties may affect its apparent sensitivity so as to give the user a false sense of security or alarm (see examples in Appendix D). So, in spite of the actual $50 \%$ height attached to each explosive by either test, these explosives should be treated with more care than would be warranted based on the Test $12 \mathrm{~A} \mathrm{Dh}_{50}$ value alone.

Generally, the user should not place much dependence on the drop-weight machine as a true measure of impact sensitivity. It is used as a convenient, cheap tool to do safety and preliminary impact evaluations of a new explosive. Informatjon so gained enables one to decide what methods or processing must be used to prepare larger quantities for larger scale performance and sensitivity tests.

The following are representative data for common explosives. All samples were pressed into pellets except for the PETN 12B test which was a loose powder sample. The number ranges given for the $12 A$ test were determined from historical data (10/76 to $9 / 94$ ) and are considered the acceptable range for calibration purposes.

Table 1

\begin{tabular}{|c|c|c|}
\hline Explosive & Test 12A $\mathrm{Dh}_{50}(\mathrm{~cm})$ & Modified Test 12B $D_{50}(\mathrm{~cm})$ \\
\hline PETN & $15 \pm 3$ & 20 \\
\hline $\mathrm{RDX}$ & $37 \pm 6$ & -- \\
\hline$H M X$ & $31 \pm 4$ & 39 \\
\hline Comp B-3 & $50 \pm 4$ & 62 \\
\hline TNT & $61 \pm 9$ & -- \\
\hline
\end{tabular}

\section{Calibration Procedure}

The calibration of the Drop Hammer machine tends to drift from its nominal state because of wear on the faces of the striker and anvil and because the vibration of numerous impacts causes parts to loosen. Therefore, a series of calibrations are done with PETN and Comp B-3 on a periodic basis (after every 20 samples tested). At this 
time the machine is adjusted as required to fix any problems before testing is resumed. Appendix $D$ is a troubleshooting guide for the impact machine, and includes the relationship between parts of the calibration procedure with problems that have been encountered with use over time.

Of the explosives listed in the previous section, PETN, RDX, and Comp B-3 are routinely used to calibrate the Drop Hammer machine. These materials cover most of the range of the machine. Because PETN has a steeper slope in a noise response vs. height plot than RDX or Comp B-3, it is especially useful for checking the integrity of the machine (Figures $2 a$ and $2 b$ ). The behavior of PETN goes out of range fastest as the machine loosens up with use and changes the nature of the compressional and rarefaction waves. For calibration, each material should be tested with a series of 30 drops. If the results fall outside of the acceptable range, there are certain parts of the machine that need to be checked for condition or security of attachment.

The first item needing attention is the bolts attaching the anvil holder to the base. These bolts are checked by using a torque wrench set to 50-ft-lbs. The bolts are torqued in an alternating pattern around the base to prevent distortion of the anvil holder. If the bolts cannot be torqued to the 50 -ft-lbs specification, they should be replaced. Calibrations are rerun after bolt adjustment is complete.

If the re-torquing of the bolts does not bring the calibrant into the acceptable range, the next item to be checked is the condition of the screen between the anvil holder and the base. The screen used is a 16-mesh stainless steel wire cloth. Its purpose is to produce a more even load distribution between the anvil holder and the base. The screen needs to be replaced periodically because impact of the falling hammer progressively flattens the screen over a period of time. If the screen is flattened too much, it causes the impact height of all materials to become artificially higher, a false measure of insensitivity. The screen is cut to the size of the base of the anvil holder with holes to allow the bolts to pass through. A new screen is placed under the anvil holder and the bolts inserted and torqued to $50-\mathrm{ft}-\mathrm{lbs}$.

The surfaces of the striker and anvil should also be checked to be sure they are in good condition. They should be checked for roughness and cracking-with the fingertips. Roughened anvils and strikers should be sent to the grinding shop for regrinding. Cracked anvils and strikers should be discarded. 
Other items that need to be checked are the condition of all electronic cabling and the calibration dates of the electronic equipment. Out-of-calibration electronic equipment and oxidized connectors can change the results of tests, sometimes causing a systematic error over a long period of time, or spuriously high/low meter readings. In addition, if the two digital voltmeters are coupled incorrectly they will not both zero properly and the two readings will not correlate well. The problem arises when the connections permit both meters to drive the microphone. To avoid this problem, one meter should be set to for transducer operation. The analog output of this meter should then be sent to the analog output of the second meter, which is set for normal meter operation.

\section{Acknowledgements}

The authors would like to thank Jon L. Maienschein and Gordon L. Moody for invaluable technical support, and LeRoy Green and Ed James for guiding this work with their extensive knowledge of small-scale testing. 


\section{References}

1 Clear, A.J., "Standard Laboratory Procedures for Sensitivity, Brisance and Stability of Explosives," Report 1401 Revision 1, Feb. 1950, Picatinny Arsenal, Dover, New Jersey.

2 Drimmer, B.E., "Navy Bank of Explosive Data (NAVBED), Volume 1," Report NSWC MP 83-230, June 1983, Naval Surface Weapons Center, Dahlgren, Virginia, and references therein.

3 Avrami, L. and Hutchinson, R. In Energetic Materials: Technology of the Inorganic Azides; Fair, H.D. and Walker, R.F., Eds.; Plenum Press: New York, 1977; pp $113-124$.

4 Walker, G.R., "Manual of Sensitiveness Tests"; The Canadian Armament Research and Development Establishment, TTCP Panel O-2 (Explosives) Working Group on Sensitiveness, Feb. 1966.

5 Dobratz, B.M., Finger, M., Green, L.G., Humphrey, J.R., McGuire, R.R., and Rizzo, H.F., "The Sensitivity of Triaminotrinitrobenzene (TATB) and TATB Formulations," Report UCID-17808, Dec. 1978, Lawrence Livermore National Laboratory, Livermore, CA.

6 Dixon, W.J. and Massey, F.J., Jr. Introduction to Statistical Analysis, 2d ed.; McGraw-Hill: New York, 1957; pp. 318-327.

7 Dixon, W.J., "The Up-and-Down Method for Small Samples," J. Am. Statistical Assoc. 1965, 60, 967-978.

8 (a) "Proceedings of the 22nd Meeting, Houston, TX, March 29-30, 1967, and of the 23rd Meeting, U.S. Naval Postgraduate School, Monterey, CA, March 28-29, 1968;" ICRPG Liquid Propellant Test Methods Working Group; CPIA Publication; pp. 29-34; (b) Recommendations on the Transport of Dangerous Goods. Tests and Criteria, 1st ed.; United Nations: New York, 1986; pp. 72-78, pp. 99-102, pp. 160-161. 


\section{Appendix A - Cross Calibration of Microphones: Definition of the "Go" Sound Level}

Early in the summer of 1994, it became apparent that the existing microphone for the drop hammer machine was not behaving normally. Over the course of a single set of 20 drops the drop height levels drifted up systematically, resulting in $\mathrm{Dh}_{50}$ values that were much too high. It was found that part of the problem was a baseline drift in the amplifier, which was repaired. There still remained a systematic upward drift, albeit slower - it was apparent over the course of several sample sets, or several hours running. It was decided to replace this old microphone with a new one. An attempt was made to cross-calibrate the "go" levels by doing a random selection of three of the standard calibrants (PETN, RDX and Comp B-3) over the range of heights considered historically acceptable. This cross calibration was intended to be a twophase process. Step one was to determine a tentative "go" sound level with new transducer based on a historical method. Using this tentative definition, the $\mathrm{Dh}_{50}$ of standard HE's should be reproducible. To find the "accepted" Dh 50 's over time, data for the four primary HE calibrants over the period of 1976 to 1994 were averaged and found to give:

$\begin{array}{ll}\text { PETN (B-509) } & 15 \pm 3 \mathrm{~cm} \\ \text { RDX (LASL) } & 37 \pm 6.5 \mathrm{~cm} \\ \text { Comp B-3 (87-208) } & 50 \pm 4 \mathrm{~cm} \\ \text { TNT (B-569) } & 61 \pm 9 \mathrm{~cm}\end{array}$

Three "secondary" calibrants were also chosen from the drop hammer database because their $\mathrm{Dh}_{50}$ values covered both lower and higher drop heights:

$$
\begin{array}{ll}
\text { K-6 (88-190) } & 14.6 \pm 0.5 \mathrm{~cm} \\
\text { RX-26-AF (B-818) } & 131.5 \pm 10.5 \mathrm{~cm} \\
\text { TATB } & >177 \mathrm{~cm} \text { (off-scale) }
\end{array}
$$

The second step was to measure a sound response curve (meter reading vs. drop height) for three primary standard calibrants by randomly choosing both material and drop height - this is a "run-down" test. TNT was not used because historically it gave more scatter in the data and its sound response was considered very sample size dependent. All samples were to be as prepared and handled as uniformly as possible 
prior to testing and stored in a dessicator before use. There were to be 15 drops for each evenly spaced height except for two heights at the fringes where fewer were indicated to save time. The heights on the table were centered about "accepted" heights: PETN - 14 to $22 \mathrm{~cm}$; RDX - 29 to $47 \mathrm{~cm}$; Comp B-3 - 42 to $58 \mathrm{~cm}$. Randomization was done to remove a systematic error in the sound level from the first to last calibrant tested from the inevitable flattening of the wire mesh, loosening of the bolts, erosion of the anvils, etc. that occurs with successive drops. After 100 drops, the $\mathrm{Dh}_{50}$ of PETN was to be remeasured to check if the machine needed adjustments. If so, the appropriate adjustments were to be made and the PETN retested until the $\mathrm{Dh}_{50}$ was acceptable before the run-down was resumed. When the calibrant response curves were completed, the voltmeter response data of the calibrants were to be plotted together. It was hoped that comparison of the tentative "go" with the overlap of the three data sets would provide a definition of final "go" sound level. Instead, this run-down testing was not completed because of too much scatter in the data. In addition, because the $10-\mathrm{V}$ range setting of the microphone's voltmeter had too high a trigger threshold, many drops did not even register on the meter ("duds"). Once the meter was set to the lower threshold $1-\mathrm{V}$ range, a simpler "go" level determination was fixed upon. The final method used to define the "go" is outlined and discussed below.

\section{Outline:}

A Define tentative "go" sound level with new transducer.

B Do baseline PETN Dh 50 with 30-drops Bruceton Method to check against for mechanical integrity of machine.

C Do 3 primary calibrants in 30-drop Bruceton method, then the secondary standards

\section{Detailed Procedure}

1) The new transducer (integrated system: PCB Piezotronics, model 106B50 pressure transducer and model 451B Digital Peakmeter) was mounted in the same position on the containment box previously occupied by the old one.

2) A tentative "go" height was determined, based to some extent on LeRoy Green's recollection of the historical definition, by two methods: 
a $\quad 30$ pellets of 35-mg each Comp B-3 (LASL) standard were pressed in the shotgun die, and the sound level measured for each for a $50-\mathrm{cm}$ drop height. This was expected to give an average sound level used historically for "go":

b $\quad 30$ powder samples of $\sim 11.6-\mathrm{mg}$ (12-mg for practical purposes) PETN (B509) standard were also tested for 50-cm drops. [This definition of a go depends on LeRoy Green's recollection that "go" $\equiv 33 \%$ reaction of the impacted $35-\mathrm{mg} \mathrm{HE}$. One might surmise from this that since $33 \%$ of $35-\mathrm{mg}=11.6-\mathrm{mg}$, drops on this sample size from well above the "accepted" PETN. Dh $50 \sim 18-\mathrm{cm}$ should give "complete" reaction.\}

When these samples were done (with A-710 PETN), the sound level was averaged for each and compared. The "go" level was found to be 1.3-V. The scatter in the data, an average of 45-drops from two days (Comp B-3 (87-208) avg. $=1.25 \pm 0.42$ $\mathrm{V}$; PETN $(A-710)$ avg. $=1.34 \pm 0.45 \mathrm{~V})$ is illustrated in the following plot:

Figure A-1

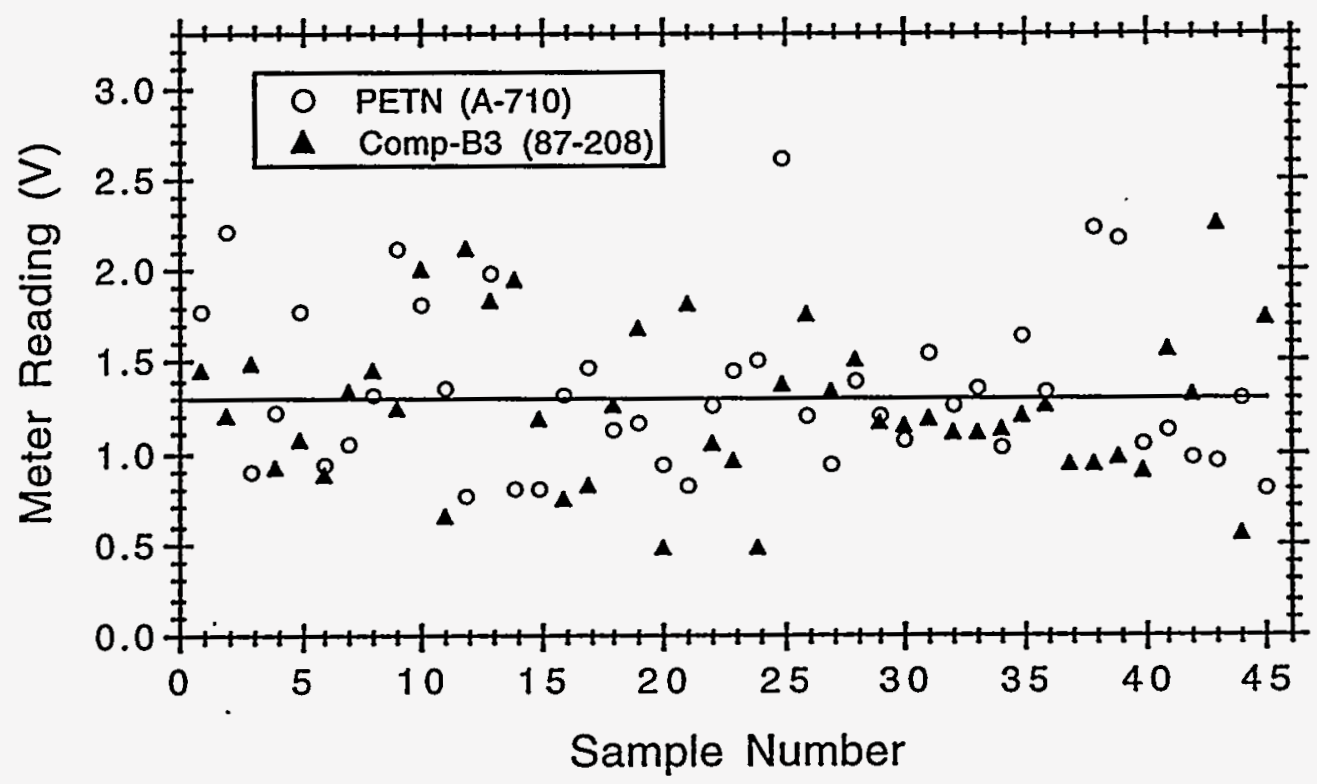

Note - The initial average of the PETN (B-509) and Comp B-3 data gave a "go" value of 1.74-V. This value changed (increased $\mathrm{Dh}_{50}$ ) later when a different batch of PETN was used (A-710). After this measurement was made, several problems were found. First the PETN batch B-509 now gave higher than accepted $\mathrm{Dh}_{50}$ values, probably as a result of being stored in a wet repository. Furthermore, the micro-Dot to BNC cable from microphone to meter had not been making good contact (symptom - spurious 
very high readings which were more frequent with use). Finally, switching to the $1-V$ range on the voltmeter meant that sound levels above $2-V$ were overrange and were not recorded (i.e the meter display went blank). By using a new batch of PETN (A710), and replacing the bad connectors, the first two problems were fixed. Sound levels producing signals over $2-\mathrm{V}$ were measured off a Tektronix 2440 oscilloscope plugged into the analog output of the meter.

3) The three calibrants were then run again with 30-drops in the Bruceton up and down method to double-check of the previously accepted $D_{50}$ values against the new "go" level.

4) The secondary standards were also run with 30-drops in the Bruceton method. The measured $\mathrm{Dh}_{50}$ values were compared with measurements made previously with the old transducer, and were found to be within the accepted range. 


\section{Appendix B - Specific Procedure}

1 Turn on electronics. Allow them to warm up for 10 to 15-min before using. Zero the two coupled voltmeters if they have drifted from zero during warm-up. They should be $A C$ coupled on the $1-\mathrm{V}$ and $10-\mathrm{V}$ ranges respectively.

2 Check anvil and striker for their condition. Check for wear on the striking surfaces with the fingertips. Also check for cracks in both parts - replace if cracked. If parts are replaced, do calibration series.

3 Check water trap and paper filter in vacuum system. Fill water trap to just above the bottom end of the intake tube. Replace paper filter element if necessary.

4 Turn on the vacuum system. Switch is located on wall to the right of the machine.

5 Zero the drop hammer. Set the height reading to 000.0. Allow hammer to descend to its lowest point. Set the height select switch to manual. With a piece of cardboard between anvil and striker, push hammer down button to adjust hammer so there is a very small amount of slack in the chain. Press readout reset button to zero height readout. Reset height select to auto. Adjust height select thumbwheels to desired height and allow hammer to rise to selected height.

6 Fill out Drophammer workbook with the following information:

\begin{tabular}{|c|c|}
\hline Matl \# & Acct.\# $\quad$ Requestor \\
\hline & Sample type: (e.g. 35-mg powder, pile, pellet, chunk, etc.) \\
\hline & Relative humidity \\
\hline & Room Temperature \\
\hline
\end{tabular}

Type of test: (e.g. Test 12A \{sandpaper\}, Test 12B \{bare anvil\}, or Liquid $\{1$ drop\})

Operator Initials Date

$\underline{X \text { (go) }} \underline{\text { O(no go) } \quad \text { Height (cm) Meter Reading (volts) }}$

7 Weight out samples $(0.035-\mathrm{gm})$. Samples are usually pressed into pellets in the "shotgun" die, weighed to \pm 2 -mg. Pellet samples are placed on 1-in square pieces of "fine" (120-grit) flint carborundum paper for the Test 12A test (for the Modified Test 
12B they are placed directly on the bare anvil). If the sample is not to be pressed, it is important that all the piles of powder be of the same size and shape on the sandpaper squares.

8 Using forceps, place the sample/sandpaper on the bottom anvil.

9 Insert the striker into the tool holder and gently lower the striker onto the sample.

10 Install polycarbonate safety shield in front of containment box. Put on ear protection.

11 Push red reset button on front of voltmeter to zero the voltage reading.

12 To drop the weight, push the enable button on the height control panel then push the drop button.

13 Record the voltage in the workbook with an " $\mathrm{X}$ " or an "O" " $\mathrm{X}$ " if the value is $\geq 1.3$ $\mathrm{V}$, "O" if $<1.3-\mathrm{V}$ ). If it is a no go, then increase the height setting one step (see chart on wall, reproduced below). If it is a go, then decrease the height setting one step.

14 Clean the anvil and striker with a razor blade and acetone-wetted wipe. Repeat steps 8 through 14 for remaining samples.

15 When finished with testing, clean residue out of containment box then wipe down the anvil and striker with sewing machine oil. Before turning off the system, the hammer must be set at 50-cm: if left at any other setting, when next turned on the lift mechanism will suddenly start up to randomly reposition (up or down) the drop weight. Place a piece of cardboard between the top and bottom anvil surfaces. Turn off the vacuum system and electronics.

16 Note for liquid samples: Use special $1.1-\mathrm{kg}$ striker with tool holder/collar - they are stored together. Make sure holder/collar fit smoothly without binding. The collar will fit into the top of the tool holder where the other $2.5-\mathrm{kg}$ striker goes. Wipe top of anvil with thin coat of high-vacuum grease between for each sample tested. Use a strong spring clamp on the striker above the collar to set the striker so the bottom face is about 2-in above the bottom anvil. The spring clamp must hold the striker tightly enough to suspend the striker above the anvil. Use a plastic (never glass - an explosion accident can result) eye-dropper to place one drop of the sample on the center of the anvil. Using a $1 / 8^{\prime \prime}$ Allen wrench as a spacer, readjust the spring clamp to lower the striker onto the wrench and anvil. Remove the Allen wrench so that the 1/8" space remains between the anvil and striker surfaces. Hereafter perform the test the same as for Test $12 \mathrm{~A}$ or $12 \mathrm{~B}$. Clean anvil surfaces as usual, but be aware that solvents other than acetone may be required to remove the vacuum grease. 


\section{Appendix C - Sample Calculation of $\mathrm{Dh}_{50}$}

The following calculation shows how the $50 \%$ drop height, or $\mathrm{Dh}_{50}$, is calculated from the Bruceton up and down impact sensitivity data. Tabulated is the raw data relating drop height $(\mathrm{cm})$ to sound reading on the voltmeter $(\mathrm{V})$, as well as whether the event was considered a "go" with a meter reading above $1.3-\mathrm{V}$, or a "no go".

Table C-1

Calibration Sample: PETN (A-710)

\begin{tabular}{|c|c|c|c|}
\hline "go" & "no go" & Height $\mathrm{h}(\mathrm{cm})$ & Meter Reading (V) \\
\hline $\mathrm{x}$ & & 17.7 & 1.738 \\
\hline $\mathrm{x}$ & & 15.8 & 2.880 \\
\hline$x$ & & 14.1 & 2.340 \\
\hline \multirow[t]{5}{*}{$\mathrm{x}$} & & 12.6 & 1.366 \\
\hline & 0 & 11.2 & 0.000 \\
\hline & 0 & 12.6 & 1.008 \\
\hline & $\mathrm{O}$ & 14.1 & 0.889 \\
\hline & 0 & 15.8 & 0.801 \\
\hline \multirow[t]{3}{*}{$\underline{x}$} & & 17.7 & 1.399 \\
\hline & 0 & 15.8 & 1.282 \\
\hline & $\mathrm{O}$ & 17.7 & 1.176 \\
\hline \multirow[t]{4}{*}{$\mathrm{X}$} & & 19.9 & 2.560 \\
\hline & 0 & 17.7 & 1.075 \\
\hline & $\mathrm{O}$ & 19.9 & 1.016 \\
\hline & 0 & 22.3 & 1.257 \\
\hline$x$ & & 22.3 & 2.020 \\
\hline$\underline{x}$ & & 19.9 & 1.967 \\
\hline \multirow[t]{2}{*}{$x$} & & 17.7 & 1.876 \\
\hline & 0 & 15.8 & 1.244 \\
\hline$x$ & & 17.7 & 1.523 \\
\hline$x$ & & 15.8 & 1.768 \\
\hline \multirow[t]{4}{*}{$x$} & $\cdot \cdot$ & 14.1 & 1.795 \\
\hline & 0 & 12.6 & 0.000 \\
\hline & 0 & 14.1 & 0.591 \\
\hline & 0 & 15.8 & 1.075 \\
\hline \multirow[t]{2}{*}{$x$} & & 17.7 & 1.641 \\
\hline & 0 & 15.8 & 1.007 \\
\hline$x$ & & 17.7 & 2.160 \\
\hline \multirow[t]{2}{*}{$x$} & & 15.8 & 2.340 \\
\hline & 0 & 14.1 & 0.929 \\
\hline
\end{tabular}


This calibrant's data can be retabulated in the following form to better illustrate how the testing sequence is applied and as an aid to the calculation:

Table C-2

Calibration Sample: PETN (A-710)

Testing Sequence

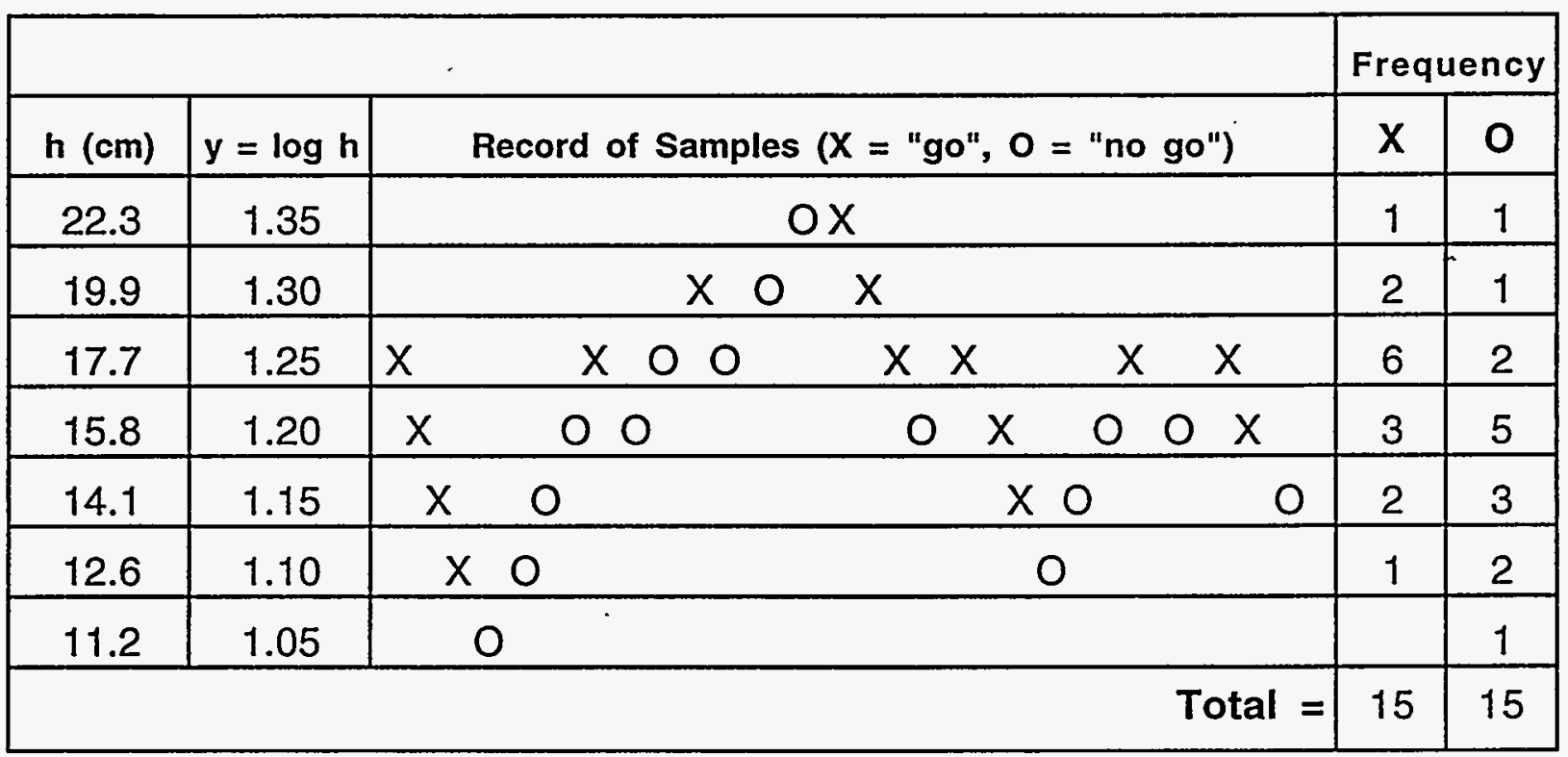

For the $\mathrm{Dh}_{50}$ calculation, the definitions are:

$N=$ number of events at each level (choose "go's" if "X's" $\leq$ "O's", choose "no go's" if "O's" < "X's")

$\mathrm{n}=$ for the type of event chosen for $\mathrm{N}$, number of levels that were picked from the drop height sequence table $y=$ normalized lowest height $\left(h_{0}\right)=\log h_{0}$ of the $N$ events $d=\log \frac{h_{1}}{h_{0}}$ (will be typically 0.05 , occasionally 0.10 , and rarely 0.15 ) $i=$ level number (i.e. the number of drops at six equally spaced heights starting with the lowest height used for " $y$ ") . 
This example's raw data reduces to:

1 number of "X's" = $\underline{15}$

2 number of "O's" $=\underline{15}$

3 plus or minus $0.5=\underline{-0.5}$ (if number of $X ' s \geq 0$ 's, will be -0.5 - otherwise it is +0.5 : this choice shows up as \pm 0.5 in the equation in step 15)

4 least height for "X's" or "O's" = 12.6 (choose "X's" since \#1 = \#2)

$5 \log$ of the least height $(y)=1.100371$

6 log interval $(d)=\underline{0.05}$

(for the following, $N_{i}$ is number of events, $i$ is the sequence number)

7 number of events at the least height $(12.6)=1$

8 number of events at next height $(14.1)=\underline{2}$

9 number of events at next height $(15.8)=\underline{3}$

10 number of events at next height $(17.7)=\underline{6}$

11 number of events at next height (19.9) $=\underline{2}$

12 number of events at next height $(22.3)=1$

(If the number of height levels above the least height exceeds six during testing, the data will be discarded and a different log interval will be chosen. This is because experience has shown the standard deviation will be very large with data from more than six levels.)

13 sum of $N_{i} \times i=\sum_{i=0}^{i=n-1} N_{i} \times i$

$$
=2(1)+3(2)+6(3)+2(4)+1(5)=\underline{39}
$$

14 sum of events for calculation $=\sum_{1}^{n} N_{n}=\# 1$ if go's chosen as events

$$
=1+2+3+6+2+1=\underline{15}
$$

$15 \log$ of $\mathrm{Dh}_{50}=\mathrm{m}$ :

$$
m=y+d \times\left[\frac{\sum_{i=0}^{i=n-1} N_{i} \times i}{\sum_{1}^{n} N_{n}} \pm 0.5\right]=\underline{1.205371}
$$

(in this case step \# 3 put -0.5 in the equation for the choice of \pm 0.5 )

$16 \mathrm{Dh}_{50}(\mathrm{~cm})=10(\mathrm{~m})=\underline{16.0} \mathrm{~cm}$ 
For the standard deviation calculation:

17 sum of $N_{i} \times i^{2}=\sum_{i=0}^{i=n-1} N_{i} \times i^{2}$

$$
=2(1)^{2}+3(2)^{2}+6(3)^{2}+2(4)^{2}+1(5)^{2}=\underline{125}
$$

18 the standard deviation, $\pm \sigma=\log s$ and

$$
s=1.620 \times d \times\left[\frac{\sum_{1}^{n} N_{n} \sum_{i=0}^{i=n-1} N_{i} \times i^{2}-\left(\sum_{i=0}^{i=n-1} N_{i} \times i\right)^{2}}{\left(\sum_{1}^{n} N_{n}\right)^{2}}+0.029\right]=\underline{0.130}
$$

19 plus $(\mathrm{cm})=10(\mathrm{~m}+\mathrm{s})-\mathrm{Dh}_{50}=\underline{5.6}$

$$
\text { or } \mathrm{Dh}_{50}(\max )=10(\mathrm{~m}+\mathrm{s})=\underline{21.6 \mathrm{~cm}}
$$

20 minus $(\mathrm{cm})=10(\mathrm{~m}-\mathrm{s})-\mathrm{Dh}_{50}=-4.1$

$$
\text { or } D_{50}(\max )=10(\mathrm{~m}-\mathrm{s})=11.9 \mathrm{~cm}
$$

The final $50 \%$ impact height calculated for this sample is $D_{50}=16.0 \frac{+5.6}{-4.1}$. Note that the there were seven height levels used - the standard deviation would be improved by going to fewer levels or to $d=0.10$. 
Table C-3

Drop Height Sequence Table for Bruceton method ${ }^{*}$

\begin{tabular}{|c|c|c|}
\hline$d=0.05$ & $d=0.10$ & $d=0.15$ \\
\hline Height $=h(\mathrm{~cm})$ & Height $=h(\mathrm{~cm})$ & Height $=h(\mathrm{~cm})$ \\
\hline 5.0 & 5.0 & 5.0 \\
\hline 5.6 & 6.3 & 7.1 \\
\hline 6.3 & 7.9 & 10.0 \\
\hline 7.1 & 10.0 & 14.1 \\
\hline 7.9 & 12.6 & 19.9 \\
\hline 8.9 & 15.8 & 28.1 \\
\hline 10.0 & 19.9 & 39.7 \\
\hline $11: 2$ & 25.1 & 56.1 \\
\hline 12.6 & 31.6 & 79.2 \\
\hline 14.1 & 39.7 & 111.9 \\
\hline 15.8 & 50.0 & 158.1 \\
\hline 17.7 & $62.9^{\circ}$ & \\
\hline 19.9 & 79.2 & \\
\hline 22.3 & 99.8 & \\
\hline 25.1 & 125.6 & \\
\hline 28.1 & 158.1 & \\
\hline \multicolumn{3}{|l|}{31.6} \\
\hline \multicolumn{3}{|l|}{35.4} \\
\hline \multicolumn{3}{|l|}{39.7} \\
\hline \multicolumn{3}{|l|}{44.6} \\
\hline \multicolumn{3}{|l|}{50.0} \\
\hline \multicolumn{3}{|l|}{56.1} \\
\hline \multicolumn{3}{|l|}{62.9} \\
\hline \multicolumn{3}{|l|}{70.6} \\
\hline \multicolumn{3}{|l|}{79.2} \\
\hline \multicolumn{3}{|l|}{88.9} \\
\hline \multicolumn{3}{|l|}{99.8} \\
\hline \multicolumn{3}{|l|}{111.9} \\
\hline \multicolumn{3}{|l|}{125.6} \\
\hline \multicolumn{3}{|l|}{140.9} \\
\hline \multicolumn{3}{|l|}{158.1} \\
\hline 177.4 & & \\
\hline
\end{tabular}

* The values of the normalized height $(y=\log h)$ are equally spaced by $\Delta y=\log h_{0}-\log h_{1}=0.50,0.10$, or 0.15 . 


\section{Appendix D - Troubleshooting Guide}

\begin{tabular}{|c|c|c|}
\hline Problem & Probable Cause(s) & Solution \\
\hline $\mathrm{Dh}_{50}$ lower than expected & $\begin{array}{l}1 \text { Microphone is not } \\
\text { responding the same as } \\
\text { when "go" level was } \\
\text { defined } \\
2 \text { Soft, oxygen-rich HE } \\
\text { may be reacting with glue } \\
\text { in sandpaper of Test } 12 \mathrm{~A} \\
\text { test }\end{array}$ & $\begin{array}{l}1 \text { Check calibrant sound } \\
\text { level using procedure } \\
\text { described in Appendix A } \\
\text { for defining "go" level } \\
2 \text { Try Modified Test 12B } \\
\text { test }\end{array}$ \\
\hline $\mathrm{Dh}_{50}$ higher than expected & $\begin{array}{l}1 \text { For PETN calibrant, this } \\
\text { indicates the machine } \\
\text { needs mechanical } \\
\text { adjustment since the steep } \\
\text { response (sound vs } \\
\text { height) of PETN is the most } \\
\text { sensitive to the machine's } \\
\text { integrity } \\
2 \text { Lead shot in hollow drop } \\
\text { weight may be deformed } \\
\text { and packed down } \\
3 \text { Anvil surfaces are too } \\
\text { worn } \\
4 \text { Drop weight machine is } \\
\text { out of plumb }\end{array}$ & $\begin{array}{l}1 \text { Make sure bolts are } \\
\text { torqued to } 50 \text {-ft-lbs. Retest. } \\
\text { Replace screen if } \mathrm{Dh}_{50} \text { not } \\
\text { acceptable, retorque bolts } \\
\text { and retest } \\
2 \text { Replace lead shot } \\
3 \text { Replace with fresh } \\
\text { anvils, grind down old } \\
\text { ones } \\
4 \text { Replumb the machine, } \\
\text { adjusting the four large } \\
\text { screws at base }\end{array}$ \\
\hline $\begin{array}{l}\text { Sporadic high voltmeter } \\
\text { readings }\end{array}$ & $\begin{array}{l}\text { Cable between } \\
\text { microphone and voltmeter } \\
\text { may have bad connection }\end{array}$ & Replace cable \\
\hline $\begin{array}{l}\text { Voltmeter reads zero after } \\
\text { a drop }\end{array}$ & $\begin{array}{l}\text { Meter did not trigger } \\
\text { because event was below } \\
\text { trigger threshold }\end{array}$ & No adjustment suggested \\
\hline
\end{tabular}




\begin{tabular}{|c|c|c|}
\hline Problem & Probable Cause(s) & Solution \\
\hline $\begin{array}{l}\text { Voltmeter display reads } \\
\text { nothing after a drop }\end{array}$ & Sound level was off-scale & $\begin{array}{l}\text { Use secondary meter on } \\
\text { higher range scale or an } \\
\text { oscillocscope to measure } \\
\text { response }\end{array}$ \\
\hline $\begin{array}{l}\text { Voltmeter readings drift } \\
\text { systematically up or down } \\
\text { during the course of one } \\
\text { sample set }\end{array}$ & $\begin{array}{l}1 \text { Layer of decomposition } \\
\text { residue may be building } \\
\text { up on microphone, } \\
\text { changing its frequency } \\
\text { response } \\
2 \text { Built-in amplifier on } \\
\text { microphone may be } \\
\text { experiencing base-line } \\
\text { drift } \\
3 \text { Microphone may be } \\
\text { failing }\end{array}$ & $\begin{array}{l}1 \text { Clean surface of } \\
\text { microphone } \\
2 \text { Check zero of amplifier } \\
\text { over comparable period of } \\
\text { time to see if drift has } \\
\text { occurred } \\
3 \text { Check calibrant sound } \\
\text { level using procedure } \\
\text { described in Appendix A } \\
\text { for defining "go" level }\end{array}$ \\
\hline $\begin{array}{l}\text { Test 12A (sandpaper) } \\
\text { Dh } \\
\text { than significantly higher } \\
\mathrm{Dh}_{50}\end{array}$ & $\begin{array}{l}\text { This HE may be potentially } \\
\text { dangerous, with a } \\
\text { deceptively high } \mathrm{Dh}_{50} \text { for } \\
\text { the "standard" test - it may } \\
\text { safely melt or flow under } \\
\text { gritty conditions but } \\
\text { undergo accidental } \\
\text { explosion otherwise }\end{array}$ & $\begin{array}{l}\text { The requestor should be } \\
\text { warned of the HE's } \\
\text { unusual impact behavior }\end{array}$ \\
\hline $\begin{array}{l}\text { Lower anvil bounces out of } \\
\text { tool holder }\end{array}$ & $\begin{array}{l}\text { Anvil was not snugly fitted } \\
\text { into place }\end{array}$ & $\begin{array}{l}\text { Wipe bottom of anvil with } \\
\text { small amount of vacuum } \\
\text { grease and twist/ring it into } \\
\text { place when setting up }\end{array}$ \\
\hline $\begin{array}{l}\text { PETN calibrant sample } \\
\text { giving higher } \mathrm{Dh}_{50} \text { than } \\
\text { expected even after } \\
\text { machine adjustment }\end{array}$ & $\begin{array}{l}\text { Material may have gotten } \\
\text { wet and chemically } \\
\text { degraded }\end{array}$ & $\begin{array}{l}\text { Replace batch with new } \\
\text { material - test } D_{50} \text { to } \\
\text { make sure it's in accepted } \\
\text { range }\end{array}$ \\
\hline
\end{tabular}




\begin{tabular}{|l|l|l|}
\hline \multicolumn{1}{|c|}{ Problem } & \multicolumn{1}{|c|}{ Probable Cause(s) } & \multicolumn{1}{c|}{ Solution } \\
\hline $\begin{array}{l}\text { Azide samples don't give } \\
\text { "go" reactions }\end{array}$ & $\begin{array}{l}\text { Samples were pressed to } \\
\text { too high a density ("dead- } \\
\text { pressed") }\end{array}$ & $\begin{array}{l}\text { Press samples to lower } \\
\text { density }\end{array}$ \\
\hline $\begin{array}{l}\text { Moderate and low } \\
\text { sensitivity iquid samples } \\
\text { don't give "go" reactions }\end{array}$ & $\begin{array}{l}\text { These liquid samples need } \\
\text { to cavitate to react - either } \\
1 \text { samples did not form a } \\
\text { bead on the anvil, or } \\
2 \text { the wrong striker was } \\
\text { used }\end{array}$ & $\begin{array}{l}1 \text { Make sure lower anvil is } \\
\text { lightly greased before } \\
\text { loading the 1-drop sample } \\
\text { 2 Use 1.1-kg striker }\end{array}$ \\
\hline $\begin{array}{l}\text { Drop weight suddenly } \\
\text { moves up or down when } \\
\text { lift mechanism is turned on }\end{array}$ & $\begin{array}{l}\text { Lift mechanism electronics } \\
\text { expects weight to be left at } \\
50 \text {-cm height and will } \\
\text { function erratically when } \\
\text { turned on if weight is not at } \\
\text { expected height }\end{array}$ & $\begin{array}{l}\text { Remember to leave-drop } \\
\text { weight at 50-cm height } \\
\text { before turning off } \\
\text { electronics }\end{array}$ \\
\hline $\begin{array}{l}\text { Inability to simultaneously } \\
\text { zero both upper and lower } \\
\text { range digital voltmeters, } \\
\text { and disagreement in } \\
\text { readings }\end{array}$ & $\begin{array}{l}\text { Check meter setting - both } \\
\text { meters may be trying to } \\
\text { drive the transducer }\end{array}$ & $\begin{array}{l}\text { Set one meter to normal, } \\
\text { the second to ICP }\end{array}$ \\
\hline $\begin{array}{l}\text { Too much scatter within } \\
\text { one data set }\end{array}$ & $\begin{array}{l}\text { Pellets may not have been } \\
\text { pressed uniformly in } \\
\text { shotgun die due to sticking } \\
\text { of pistons }\end{array}$ & $\begin{array}{l}\text { Make sure die is well- } \\
\text { cleaned so all pellets are } \\
\text { uniformly pressed }\end{array}$ \\
\hline
\end{tabular}

